\title{
Article \\ Fully Biobased Reactive Extrusion of Biocomposites Based on PLA Blends and Hazelnut Shell Powders (HSP)
}

\author{
Luca Panariello $^{1,2, *(\mathbb{D})}$, Maria-Beatrice Coltelli ${ }^{1,2, *(\mathbb{D}}$, Alessandro Vannozzi ${ }^{2}$, Daniele Bonacchi ${ }^{3}$, \\ Laura Aliotta 1,2 and Andrea Lazzeri 1,2 \\ 1 Department of Civil and Industrial Engineering, University of Pisa, 56122 Pisa, Italy; \\ laura.aliotta@unipi.it (L.A.); andrea.lazzeri@unipi.it (A.L.) \\ 2 National Interuniversity Consortium of Materials Science and Technology (INSTM), 50121 Florence, Italy; \\ alessandrovannozzi91@hotmail.it \\ 3 Arianna Fibers s.r.l., 51100 Pistoia, Italy; d.bonacchi@ariannafibers.com \\ * Correspondence: luca.panariello@ing.unipi.it (L.P.); maria.beatrice.coltelli@unipi.it (M.-B.C.)
}

Citation: Panariello, L.; Coltelli, M.-B.; Vannozzi, A.; Bonacchi, D.; Aliotta, L.; Lazzeri, A. Fully Biobased Reactive Extrusion of Biocomposites Based on PLA Blends and Hazelnut Shell Powders (HSP). Chemistry 2021, 3, 1464-1480. https://doi.org/ $10.3390 /$ chemistry3040104

Academic Editor: Pietro Russo

Received: 9 November 2021

Accepted: 2 December 2021

Published: 5 December 2021

Publisher's Note: MDPI stays neutral with regard to jurisdictional claims in published maps and institutional affiliations.

Copyright: (c) 2021 by the authors. Licensee MDPI, Basel, Switzerland. This article is an open access article distributed under the terms and conditions of the Creative Commons Attribution (CC BY) license (https:// creativecommons.org/licenses/by/ $4.0 /)$.

\begin{abstract}
The production of biocomposites based on natural fiber waste and biopolymers is constantly increasing because of their renewability, biodegradability, and the accordance with the circular economy principles. The aim of this work is to contrast the disadvantages in the production of biocomposites, such as reduction of molecular weight through the use of biobased chain extenders. For this purpose, epoxidized soybean oil (ESO) and dicarboxylic acids (DCAs) were used to contrast the slight chain scission observed in a poly(lactic acid) (PLA)/poly(butylene succinate-co-adipate) (PBSA) binary blend caused by the melt mixing with hazelnut shell powder (HSP). Two different dimensions of HSPs were considered in this study as well as different concentrations of the ESO/DCA system, comparing succinic acid and malic acid as dicarboxylic acids. Melt viscosity parameters, such as torque and melt volume rate (MVR), were measured to investigate the chain extender effect during the extrusion. In addition, the reactivity of the ESO/DCA system was investigated through infrared spectroscopy. The effect of chain extenders on thermal properties, in particular on the crystallinity of PLA, and on mechanical properties of final biocomposites was investigated to understand their potentialities in industrial application. Results of this study evidenced a modest increase in melt viscosity due to ESO/malic acid chain extension system, but only for the HSP with the lower dimension (so the higher surface area) and adding $0.5 \mathrm{wt} . \%$ of ESO/malic acid. Thus, the slight chain scission of polyesters, not significantly affecting the final properties of these biocomposites, is the most relevant effect that was revealed in this complex reactive system.
\end{abstract}

Keywords: poly(lactic acid); poly(butylene succinate-co-adipate); epoxidized soybean oil; succinic acid; malic acid; biocomposites; biobased thermoset resin; hazelnut shell powder; chain extender

\section{Introduction}

Bioplastics are considered an environmentally-friendly alternative to replace fossilbased plastics [1]. The use of bioplastics is particularly interesting in fields such as packaging because of their recyclability and compostability that guarantee a versatile and sustainable end-of-life [2]. Additionally, their use in a wide range of applications in the biomedical field for the preparation of scaffolds [3], wound dressing [4,5], and artificial membranes [6] was enabled thanks to their biocompatibility [7] and bioresorbability [8]. Moreover, most bioplastics can be synthetized directly from renewable resources or from living organisms such as bacteria, fungi, and plants [9]. A significant group of biobased materials is represented by composites where natural fillers such as flax, wood, hemp or cellulose fibres, cellulose nanowhiskers, bran, nuts or wood flour are embedded in a biodegradable plastic matrix, since this strategy leads to fully biodegradable materials [10-12]. Moreover, the hydrophilicity of natural fillers can accelerate the degradation kinetic of bio- 
composites, favouring the adhesion and proliferation of microorganisms and biofouling phenomena $[13,14]$.

Among the natural sources derived from agriculture waste, nut shells can be materials of considerable interest because of their wide availability. The most important production of nut waste derives from the markets of ground nut, with a production over 41 million tons/year, but also walnut, cashew nut, hazelnut, that represent productions ranging from 500,000 to 1 million tons/year. All these kinds of nuts are used for human nutrition because they are rich in healthy oils and fats but they showed potentialities also in other sectors linked to skin care. For example, argan nut was found useful to produce both edible oil and cosmetics [15-18].

Nut waste can be used as a valid green alternative source for energy production with a reduced carbon footprint in respect to common fuels such as wood pellets [19-21], for the production of filters in water treatment [22], or as reinforcing materials in sectors such as building [18] or packaging [23].

One of the most interesting nut shell wastes is represented by hazelnut shells. This type of waste is composed of $90 \%$ of a lignocellulosic fraction ( $51.3 \%$ holocellulose, $38.7 \%$ lignin [24]) with crude fiber accounting for over $85 \%$ and the remaining part mainly composed by proteins $(2-4 \%)$, ashes $(0.8-2 \%)$, and oils $(0.3-0.7 \%)$ rich in phenolic compounds $[25,26]$. Considering the high amount of lignin and a predominantly fibrous structure, the hazelnut shell is considered a highly stiff material [24]. Thus, it can be considered suitable as mechanical reinforcement for the production of biocomposites.

Materials composed by a polymer matrix and a lignocellulosic filler are recently grouped under the name of wood plastic composites (WPCs). The use of WPCs with biodegradable matrix is one of the most attractive applications of these composites because it creates a reinforced, fully biodegradable material with a similar appearance to wood $[27,28]$.

Clearly, the success of WPC production is based on the interaction between matrix and filler that allows the achievement of good final mechanical properties. For this reason, the modification of the matrix and/or the filler with coupling agents that improve the adhesion of inorganic fillers to the polymer matrix by physical or chemical interactions is often required [29,30]. A good adhesion is in fact fundamental to efficiently transfer the bearing load from the matrix to the fibers [31].

An alternative way to improve the polymer-filler interaction is represented by cross-linker systems, which allow the formation of a polymeric network through inter-macromolecular bonds formation [32]. The choice of a crosslinker agent able to react with both polymer and filler can induce the formation of a polymeric network with covalently bonded fibers or particles. These molecules, called chain extenders, were widely used to obtain polymers with an increased molecular weight [32,33]. Nowadays, chain extenders are extensively used with biopolymers, both in their synthesis by polymerization and during melt compounding, extrusion, or injection molding of the final product [34]. Chain extenders in biopolymers can be also used as compatibilizers, for example with other polymers [35] or inorganic filler [36], but also to increase molecular weight of polymers [37], often to counterbalance chain scission occurring during their processing.

The use of chain extenders in the recycling process can result in the increase of melt viscosity, thermal stability, and mechanical properties of biopolymers [38]. This strategy is widely used and very efficient for PLA-based blends, used in a wide range of applications [37,39-42].

One of the most used chain extenders is represented by the group of products commercialized with the name of Joncryl ADR, epoxidized styrene-acrylic copolymers produced by BASF company. In literature there are many applications of Joncryl reported, such as a compatibilizer between PLA and PMMA, a melt and viscosity enhancer in PLA/PBAT blend, or chain extender for PLA/PBS $[40,43,44]$.

A chain extender can be also used to increase the performances of biocomposites increasing the surface interaction between matrix and filler and favouring their dispersion. 
For example, it was reported that the addition of a chain extender in a PLA/PBS system incorporating microcrystalline cellulose (MC) resulted in a higher impact strength than the reference composite [45].

The study of biobased chain extenders should be considered fundamental in the production of biocomposites, where a biobased and/or biodegradable additive is preferred [46,47]. Possible alternatives to fossil-based chain extenders can be represented by the various types of agro-based polymer products derived from cardanol, itaconic acid, tannin, sugar (isosorbide), and vegetable oils as starting materials due to their abundant availability, low price, and unique reactive chemical structure [46]. In the last decades, natural oils were modified by introducing functional groups, for instance by epoxidation, to increase their use in the production of lubricants, paints, coatings, or biodiesel [48-51]. Regarding PLA-based biopolymers, it is reported that epoxidized vegetable oils (EVO) have a good miscibility and interfacial adhesion with PLA [52]. However, their effectiveness as chain extenders is limited by the number of epoxy groups in the vegetable oil molecule. Since the epoxidation reaction takes place on the double bonds present on the vegetable oil molecules, which is generally limited at two groups for each fatty acid chain, their efficiencies as crosslinker agent is limited [53]. In fact, their addition into PLA-based biopolymers results more in plasticization rather than in chain extension [54,55].

Recent studies on biobased thermosetting polymers from vegetable oils reported that EVO can be used as thermoset if they are used in combination with hardeners such as biobased amines, acids, anhydrides, phenols, alcohols, and thiols [56,57]. The use of these systems as innovative chain extenders for PLA-based polymer and composites is still a very recent topic and up to now few studies are present. The main novelty is the selection of innovative chain extenders that can replace the fossil-based systems to compatibilize and contrast the thermal degradation and hydrolytic chain scission of PLA-based composites with natural fibres. In a recent study, the reaction between epoxidized soybean oil (ESO) and biobased dicarboxylic acid (DCA) was investigated in composites containing wheat bran [47], where an increase in melt viscosity was observed in case of an epoxide-carboxylic group 1:1 mole ratio and for specific contents of the chain extender system in the polymer matrix ranging between 0.5 and $5 \%$ by weight. In this work, both malic acid and succinic acid were investigated as possible dicarboxylic acids improving the reactivity of ESO. The selected matrix for the composite is the blend PLA/PBSA 60:40 [47], showing a good balance of stiffness and ductility [58].

In the present paper the same process was studied, but replacing wheat bran with hazelnut shell powders. Several parameters were considered. In particular, hazelnut shell powders (agro-food waste) having two different dimensions were used in the biocomposites preparation. Moreover, malic acid and succinic acid were compared as dicarboxylic acid components in the chain extension system and composites were prepared increasing the concentration of ESO/DCA from 0.5 to $2 \%$ by weight. The change of the melt viscosity due to the chain extension and the infrared characterization were considered for deducting the main chemical paths occurring in the melt biocomposites. Moreover, the investigation of the thermal and mechanical properties of the biocomposites was carried out to correlate them to the occurred processes, thus evidencing eventual potentialities in several final applications.

\section{Materials and Methods}

\subsection{Materials}

Poly (lactic acid) (PLA), trade name Luminy LX175, was provided by Total Corbion (Gorinchem, The Netherlands). PLA was produced from a natural source, appears as a white pellet and has a content of L-isomer of $96 \%$ [density: $1.24 \mathrm{~g} / \mathrm{cm}^{3}$; melt flow index (MFI) $\left.\left(210{ }^{\circ} \mathrm{C} / 2.16 \mathrm{~kg}\right): 6 \mathrm{~g} / 10 \mathrm{~min}\right]$.

Poly (butylene succinate-co-adipate) (PBSA), trade name BioPBS FD92PM, was purchased by Mitsubishi Chemical Corporation (Tokyo, Japan). PBSA is a soft and flexible 
polymer from a renewable source that also appears as a white pellet [density: $1.24 \mathrm{~g} / \mathrm{cm}^{3}$; MFI $\left.\left(190{ }^{\circ} \mathrm{C}, 2.16 \mathrm{~kg}\right): 4 \mathrm{~g} / 10 \mathrm{~min}\right]$.

Two different KERN hazelnut shell powders (HSPs) with different granulometry were provided by Arianna Fibers (Pistoia, Italy). HSP with a coarser grain size are named H0210 while those with a finer grain size are named HM200 $\left[\rho=954.8\right.$ to $1079.4 \mathrm{~kg} / \mathrm{m}^{3}$ with HR 5 to $30 \%$ ] [59].

Epoxidized soybean oil (ESO), was purchased by Alcoplast (Vercelli, Italy) and appears as a light-yellow liquid [epoxide number: 4.1 (mean number of epoxy group for molecule of ESO), [molecular weight: $950 \mathrm{~g} / \mathrm{mol}$, density: $0.664 \mathrm{~g} / \mathrm{cm}^{3}$ ].

L-malic acid (MA), was provided by OENO S.r.l. (Erbusco, Italy) and it is a white, odorless powder [molecular weight: $134.1 \mathrm{~g} / \mathrm{mol}$ ].

Succinic acid (SA), was purchased by Carlo Erba Reagents S.r.l. (Cornaredo, Italy) and it is a white and odorless powder [molecular weight: $118.1 \mathrm{~g} / \mathrm{mol}$ ].

Chloroform RPE-for analysis, was purchased by Carlo Erba Reagents S.r.l. (Cornaredo, Italy).

\subsection{Methods}

In this paper the effect of ESO/dicarboxylic acid systems on ternary systems composed by a PLA/PBSA based matrix in combination with hazelnut shell powder was studied. A polymeric matrix reference blend composed by 60 wt.\% of PLA Luminy LX 175 and $40 \mathrm{wt} . \%$ of PBSA BioPBS-FD92PM was selected. The polymeric blend was prepared in a semi-industrial twin screw extruder Comac EBC 25HT (L/D = 44) (Cerro Maggiore, Italy). Pellets were dried before extrusion in a Piovan DP 604-615 dryer (Verona, Italy). The choice of this formulation was based on previous work [60] and it was used for all the formulations prepared in this paper.

Nutshell powders were modified with different concentrations of ESO and dicarboxylic acids (SA or MA). A concentration of $0.5,1$ and $2 \mathrm{wt} . \%$ of mixture ESO + dicarboxylic acids in respect to the weight of HSP was used as a modifier.

The evaluation of molar ratio between ESO and dicarboxylic acids required a consideration about the stoichiometry of the curing reaction. It was reported in many articles that the reaction between a dicarboxylic acid (DCA), such as SA or MA, and an epoxy group can be classified as a ring opening reaction [61-63]. As a molecule of ESO contains many epoxy groups and dicarboxylic acid can react with two epoxy groups, the reaction forms a crosslinked product. A scheme of possible reactions between ESO and DCA was reported in Figure 1.

Proper utilization of epoxy precursors to be formulated in the correct proportion required the evaluation of epoxy equivalent weight (EEW), defined as the weight of resin in grams, which contains 1 equivalent of oxirane (epoxy group) [64] and calculated as reported in Equation (1):

$$
\mathrm{EEW}=\mathrm{MW} / \mathrm{e}_{\mathrm{n}}
$$

where MW is the molecular weight of one molecule of $\mathrm{ESO}$ and $\mathrm{e}_{\mathrm{n}}$ is the epoxide number. Technical data sheet of ESO report a molecular weight $950 \mathrm{~g} / \mathrm{mol}$ and an epoxide number of 4.1, from which it is possible to calculate an epoxy equivalent weight of $232 \mathrm{~g}$ /equivalent.

The stoichiometric weight ratio (SWR) between ESO and DCA was thus defined by Equation (2):

$$
\mathrm{SWR}=\mathrm{EEW} / \mathrm{MW}_{\mathrm{DCA}}
$$

where $\mathrm{MW}_{\mathrm{DCA}}$ is the molecular weight of dicarboxylic acid divided for the number of carboxylic groups in each molecule. On the basis of Equation (2), the stoichiometric weight ratios for $\mathrm{ESO} / \mathrm{MA}$ and $\mathrm{ESO} / \mathrm{SA}$ were calculated, which resulted in $3.46 \mathrm{eq} / \mathrm{mol}$ and $3.92 \mathrm{eq} / \mathrm{mol}$, respectively.

Different blends at constant stoichiometric weight ratios were prepared fixing $80 \mathrm{wt} . \%$ of polymer matrix and $20 \mathrm{wt} . \%$ including nutshell powder and modifier. The choice of this formulation was based on literature where it was reported that modification of polyesters 
with $20 \mathrm{wt} . \%$ of natural fibers was a good compromise between an increment in mechanical properties without incurring an excessive embrittlement of the composite [65-68].

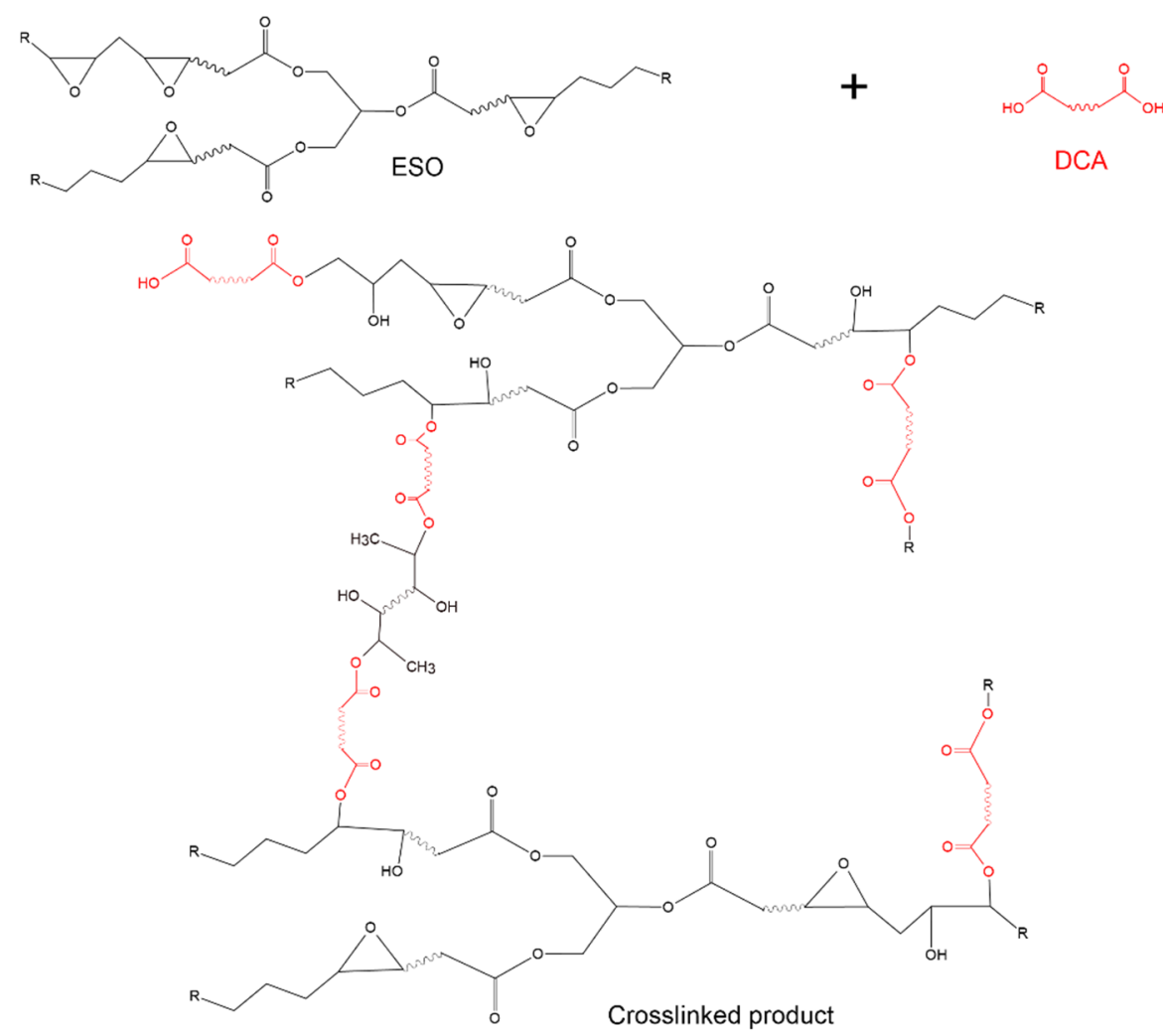

Figure 1. Scheme of reaction between ESO and DCA. A final branched structure can be observed.

In Table 1 the compositions of the prepared blends were reported.

Table 1. Weight composition of prepared biocomposites.

\begin{tabular}{cccccc}
\hline Sample & PLA/PBSA (wt. $\%)$ & H0210 $(w t . \%)$ & HM200 (wt. $\%)$ & ESO+MA (wt.\%) & ESO+SA (wt. \%) \\
\hline F1 & 100 & - & - & - & - \\
F2 & 80 & 20 & - & - & - \\
F3 & 80 & - & 20 & - & - \\
\hline F4 & 80 & 19.5 & - & 0.5 & - \\
F5 & 80 & 19 & - & 1 & - \\
F6 & 80 & 18 & - & 2 & 0.5 \\
\hline F7 & 80 & 19.5 & - & - & 2 \\
F8 & 80 & 19 & - & - & - \\
F9 & 80 & 18 & - & - & - \\
\hline F10 & 80 & - & 19.5 & 0.5 & - \\
F11 & 80 & - & 19 & 1 & 0.5 \\
F12 & 80 & - & 18 & 2 & 1 \\
\hline F13 & 80 & - & 19.5 & - & 2 \\
F14 & 80 & - & 19 & - & \\
F15 & 80 & - & 18 & - & \\
\hline
\end{tabular}

The biocomposites production, from F4 to F15, included a preliminary step of fibers modification with ESO+DCA. The fibers modification was carried out in a beaker under magnetic stirring in which a weighted amount of ESO+DCA in $150 \mathrm{~mL}$ of ethanol was firstly dissolved. After complete dissolution the HSP was slowly added trying to avoid aggregation phenomena. The suspension was left under mechanical stirring under a fume hood until total evaporation of the solvent. Then it was placed in an oven for $24 \mathrm{~h}$ at $40{ }^{\circ} \mathrm{C}$ for completing the evaporation of ethanol. The compact dried mass was then softly grinded to crush the aggregates and then put again in the oven for $24 \mathrm{~h}$ at $40{ }^{\circ} \mathrm{C}$. The 
HSP used for F2 and F3 did not undergo the preliminary treatment but it was placed in the oven for $48 \mathrm{~h}$ at $40{ }^{\circ} \mathrm{C}$ to replicate the same heat treatment of the HSP used in the other formulations. All the blends were prepared by the addition of all the components in a micro-extruder Haake Minilab II (Thermo Scientific Haake GmbH, Karlsruhe, Germany). The materials flowed through a close loop for 1 minute with a rotating speed of $110 \mathrm{rpm}$ and a temperature of $190^{\circ} \mathrm{C}$. During this time the torque data was acquired by the software Thermo Haake Polylab (Thermo Scientific Haake GmbH, Karlsruhe, Germany). The material coming out from the mini-extruder was partially collected and transferred to an Haake Minijet injection moulder (Thermo Scientific Haake GmbH, Karlsruhe, Germany) to prepare tensile specimens. Injection molding parameters were set with a cylinder temperature of $190{ }^{\circ} \mathrm{C}$, mold temperature of $45^{\circ} \mathrm{C}$, injection pressure of 650 bar for $15 \mathrm{~s}$, and a post-pressure of 200 for $5 \mathrm{~s}$. The remaining part of the extruded material was used for other characterization tests.

While the reactivity between ESO/DCA and its interaction with PLA matrix was demonstrated in literature [58], the evaluation of the reactivity between ESO/DCA and HSP was investigated in this paper. F12 and F15, the samples prepared with the HM200 and, respectively, with the highest amount of MA (or SA) with ESO were dissolved in chloroform, a good solvent for the matrix system but not for HSP [69]. After $24 \mathrm{~h}$ under stirring the solution was filtered and washed many times with chloroform. Residue powder on the filter was dried overnight at $60^{\circ} \mathrm{C}$. Dried powder was analyzed with an infrared spectrometer Nicolet 380 (Thermo Fisher Scientific, Carlsbad, CA, USA) equipped with an attenuated total reflection (ATR) smart ItX accessory (Thermo Fisher Scientific, Carlsbad, CA, USA). Spectra were recorded in the range $550-4000 \mathrm{~cm}^{-1}$ collecting 256 scans with a resolution of $4 \mathrm{~cm}^{-1}$. The spectra of $\mathrm{F} 1$ and $\mathrm{F} 3$ were also acquired as reference spectra as well as the raw HSP (HM200) that underwent the same treatment step as F12 and F15.

Tensile tests were performed with a Universal tensile testing machine MTS Criterion model 43 (MTS System Corporation, Eden Prairie, MN, USA) equipped with a $10 \mathrm{kN}$ load cell. Tests were carried out on Haake Type III specimens $(25 \mathrm{~mm} \times 5 \mathrm{~mm} \times 1.5 \mathrm{~mm})$, with an initial grip separation of $25 \mathrm{~mm}$ and a constant deformation rate of $10 \mathrm{~mm} / \mathrm{min}$.

Melt behavior was investigated with a CEAST Melt Flow Tester model M20 (Instron, Norwood, MA, USA). Tests were conducted according to the ISO1133D using a custom TTT method. The sample was manually inserted in the chamber with a piston that remained at $190{ }^{\circ} \mathrm{C}$ for $40 \mathrm{~s}$, then a weight of $2.160 \mathrm{~kg}$ was released on the piston. After $5 \mathrm{~s}$ from the release of the weight the machine cut the polymer strand and started the measurement for $60 \mathrm{~s}$, acquiring a point every $3 \mathrm{~s}$. Melt volume rate (MVR) was measured directly by the instrument through an encoder, the melt flow rate (MFR) was determined weighting the material flowed out in $60 \mathrm{~s}$, and the melt density was calculated as the ratio between MFR and MVR.

Thermal properties were investigated with a differential scanning calorimeter (DSC) TA-Q200 (Waters, Milford, CT, USA) equipped with an RSC 90 cooling system. A first heating ramp was performed from $-70{ }^{\circ} \mathrm{C}$ to $190^{\circ} \mathrm{C}$ at $10^{\circ} \mathrm{C} / \mathrm{min}$ to remove the thermal history. The sample was then cooled to $-70{ }^{\circ} \mathrm{C}$ at $10{ }^{\circ} \mathrm{C} / \mathrm{min}$, held for $1 \mathrm{~min}$ at this temperature, and then a second heating ramp was performed from $-70^{\circ} \mathrm{C}$ to $190{ }^{\circ} \mathrm{C}$ at $10^{\circ} \mathrm{C} / \mathrm{min}$. In addition to the main thermal transition (melting temperature, crystallization and cold crystallization temperature, glass transition temperature) the effect of modified and unmodified HSP on the crystallinity of PLA was evaluated. Crystallinity of PLA $\left(\mathrm{X}_{\mathrm{C}, \mathrm{PLA}}\right)$ was determined as reported in Equation (3):

$$
\mathrm{X}_{\mathrm{C}, \mathrm{PLA}}=\frac{\Delta \mathrm{H}_{\mathrm{m}, \mathrm{PLA}}-\Delta \mathrm{H}_{\mathrm{cc}, \mathrm{PLA}}}{\Delta \mathrm{H}_{\mathrm{m}, \mathrm{PLA}}^{0} \cdot \mathrm{X}_{\mathrm{PLA}}}
$$

where $\Delta \mathrm{H}_{\mathrm{m}, \mathrm{PLA}}$ and $\Delta \mathrm{H}_{\mathrm{m}, \mathrm{PLA}}$ are, respectively, the melting and cold crystallization enthalpy of PLA measured on the second ramp of DSC thermogram, $\Delta \mathrm{H}^{0}{ }_{\mathrm{m}, \mathrm{PLA}}$ is the melting enthalpy of 100\% crystalline PLA, equal to $93.1 \mathrm{~J} / \mathrm{g}$ [70] and $X_{\mathrm{PLA}}$ is the weight fraction of PLA (equal to 0.6). 


\section{Results}

\subsection{Melt Flow Analysis}

The effect of modified and unmodified HSP on the polymer blend was investigated comparing torque and melt flow results. All the values were reported in Table 2.

Table 2. Torque and melt flow results of different biocomposites.

\begin{tabular}{ccccc}
\hline Sample & Torque $\mathbf{( N \cdot c m )}$ & MFR $(\mathbf{g} / \mathbf{1 0} \mathbf{~ m i n})$ & MVR $\left(\mathbf{c m}^{\mathbf{3}} / \mathbf{1 0} \mathbf{~ m i n}\right)$ & Melt Density $\mathbf{( g / \mathbf { c m } ^ { 3 } )}$ \\
\hline F1 & $64 \pm 4$ & $3.3 \pm 0.5$ & $2.8 \pm 0.7$ & 1.16 \\
F2 & $124 \pm 8$ & $4.5 \pm 0.1$ & $3.6 \pm 0.2$ & 1.25 \\
F3 & $105 \pm 17$ & $6.5 \pm 0.1$ & $5.4 \pm 0.1$ & 1.20 \\
\hline F4 & $126 \pm 6$ & $4.7 \pm 0.2$ & $3.9 \pm 0.3$ & 1.23 \\
F5 & $123 \pm 6$ & $5.4 \pm 0.1$ & $5.0 \pm 0.6$ & 1.09 \\
F6 & $106 \pm 3$ & $6.1 \pm 0.2$ & $5.3 \pm 0.4$ & 1.15 \\
\hline F7 & $127 \pm 5$ & $4.5 \pm 0.2$ & $3.8 \pm 0.4$ & 1.18 \\
F8 & $120 \pm 11$ & $5.2 \pm 0.2$ & $4.2 \pm 0.2$ & 1.22 \\
F9 & $104 \pm 8$ & $7.0 \pm 1.1$ & $6.1 \pm 1.3$ & 1.15 \\
\hline F10 & $114 \pm 12$ & $6.0 \pm 0.4$ & $4.9 \pm 0.4$ & 1.22 \\
F11 & $113 \pm 4$ & $6.8 \pm 0.3$ & $5.6 \pm 0.3$ & 1.22 \\
F12 & $106 \pm 2$ & $7.6 \pm 0.7$ & $6.3 \pm 0.7$ & 1.20 \\
\hline F13 & $116 \pm 3$ & $7.9 \pm 0.3$ & $6.6 \pm 0.2$ & 1.19 \\
F14 & $114 \pm 3$ & $7.6 \pm 0.3$ & $6.2 \pm 0.3$ & 1.22 \\
F15 & $109 \pm 4$ & $7.8 \pm 0.1$ & $6.5 \pm 0.2$ & 1.19 \\
\hline
\end{tabular}

The torque column reported the value at $60 \mathrm{~s}$, which represents the real value of the processed material at the end of extrusion.

The analysis of the data in Table 2 showed a clear difference between the pure matrix (F1) and the composites that had higher torque values and higher MVR and MFR, indicating the presence of interaction between the matrix and the fillers. Comparing the effect of the coarser HSP (F2) in respect to the finest one (F3), it was shown a lower torque value for the finest HSP. This result can be explained considering that HSPs induces into the polymeric matrix some chain scission caused by the reactions between their surface groups (mainly hydroxyl groups on holocellulose component) or the humidity content with biopolyesters $[47,59,71]$. In fact, it was reported that the hydrolytic scission of ester bond of PLA and its composites was mainly caused by the diffusion of water in the amorphous region and the presence of $-\mathrm{OH}$ groups [72]. Augustin-Salazar et al. confirmed the degradation effect of nutshell on polyesters reporting that the onset of thermal degradation in PLA-based biocomposites with pecan nutshells assume the lowest values if mixed with the holocellulosic fraction in respect to the lignin or the whole nutshell [73]. Moreover, despite that the HSPs were dried before extrusion, some residual humidity could be also present in the hygroscopic cellulosic material [59].

Regarding the samples from F4 to F15, the addition of different amounts of ESO/DCA influenced all the composites in a similar way, with a reduction of torque at higher concentrations of ESO/DCA, especially in samples that contained the coarser HSP (from F4 to F9) where the highest concentration of ESO/DCA (F6 and F9) produced a reduction in torque of $20 \mathrm{~N} \cdot \mathrm{cm}$. This descending trend of torque is in agreement with literature because it is reported that ESO can be a plasticizer for this blend [74]. Decreasing of torque can be also ascribed at the occurrence of hydrolysis during the extrusion.

The use of SA in respect to MA did not significantly influence the torque but there were some differences in MVR and MFR, especially in the samples containing HM200 (from F10 to F15). In fact, the modification of this type of HSP with 0.5 and $1 \mathrm{wt}$ \% of ESO/MA (samples F10 and F11) did not relevantly induce changes in MVR and MFR, with a MVR value of F10 that is even lower than the reference (F3). Conversely, the addition of ESO/SA provoked an increase in MVR and MFR also at low concentration, indicating a poorer effectiveness of the system ESO/SA than ESO/MA as chain extender. 
In Figure 2 the trends of torque values were shown comparing different samples. Relevant differences can be observed in Figure 2a that represents the comparison between the pure matrix (F1) and the composite with the raw HSPs (F2 and F3). In fact, values of torque vs. time of F1 were almost constant while the composites showed descending curves. Moreover, analyzing data reported in Table 3, that represent the difference of torque values at the beginning and at the end of the extrusion, it is also clear that F2 had a higher impact on torque decay than F3. As concern samples containing ESO/DCA systems, they presented a similar descending trend as a function of time. Torque differences reported in Table 3 from F4 to F15 showed nonrelevant differences between them and their relative references (F3 and F4), suggesting that the ESO/DCA systems did not significantly affect the degradation of polymers that depends only on the type of HSP.

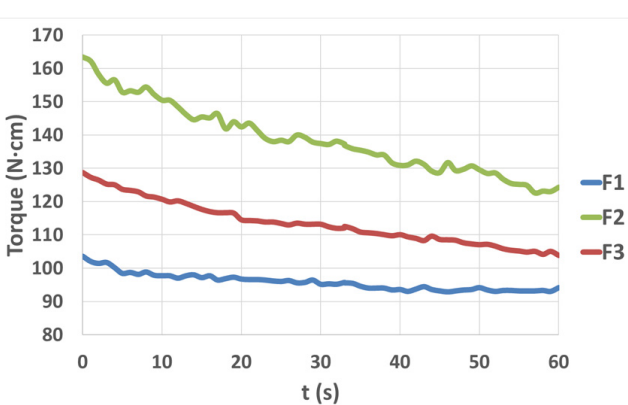

(a)

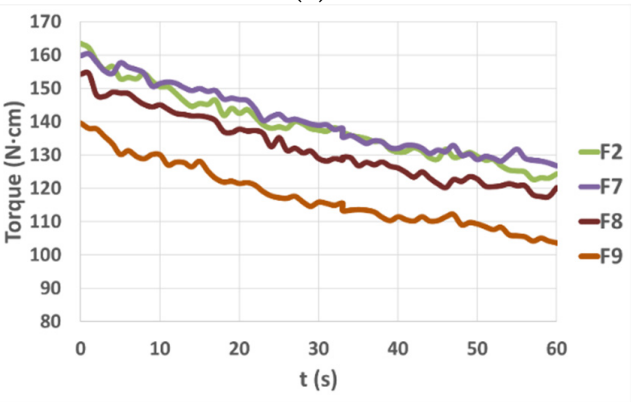

(c)

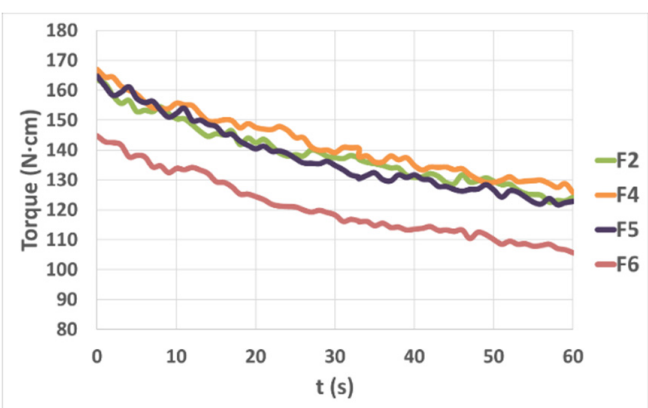

(b)

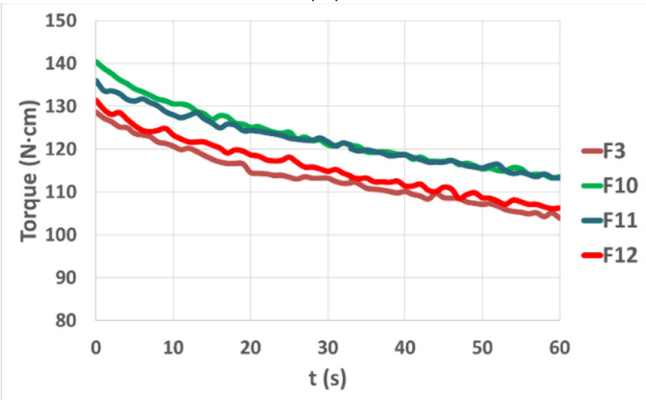

(d)

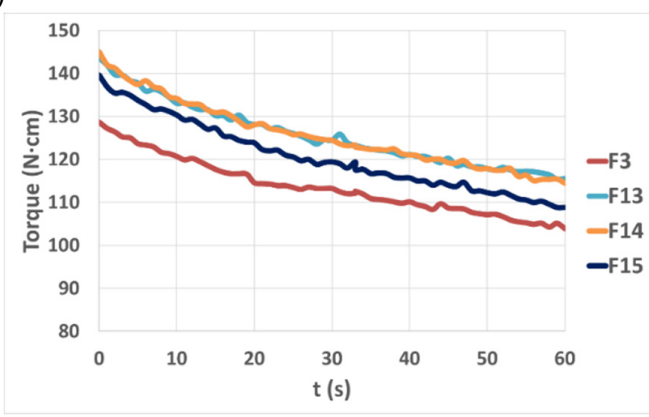

(e)

Figure 2. Torque values of: (a) pure matrix (F1) and untreated HSP (F2, F3); (b) H0210 (F2) and $\mathrm{ESO}+\mathrm{MA}$ at different concentrations (F4, F5, F6); (c) H0210 (F2) and ESO/SA at different concentrations (F7, F8, F9); (d) HM200 (F3) and ESO+MA at different concentrations (F10, F11, F12); (e) HM200 (F3) and ESO/SA at different concentrations (F13, F14, F15).

Trends of MVR as a function of time recorded during the test were reported in Figure 3. All the graphs showed an ascendant trend except for the pure matrix (F1). Hence, the 1minute extrusion did not provoke the thermal degradation of the pure matrix but significant chain scission was promoted in the presence of the filler, which resulted in an increase in slope for trend of F2 and F3 with respect to F1. Although the HSP was accurately dried before use, it was found to retain bound water, which is released only during extrusion 
provoking the hydrolysis of the matrix [59]. Regarding the differences in trends of the two HSP typologies, a higher effect of the ESO/DCA systems can be observed on the coarser powder in respect to the finest one. The finest particles, with a higher surface area, have a greater interaction with ESO/DCA and the matrix. ESO/DCA resulted thus mainly in chain scission combined with the coarser HSP in respect to the finer ones. Only slight differences in trends could be observed comparing SA and MA. The unique composite showing a lower MVR than not compatibilized composite was F10, containing the lowest amount of ESO/MA and the finest HSP.

Table 3. Difference of torque values between the beginning $\left(\mathrm{T}_{0}\right)$ and the end $\left(\mathrm{T}_{\mathrm{f}}\right)$ of the extrusion process for all the prepared samples. Higher torque differences represent a faster decay of torque over time.

\begin{tabular}{cc}
\hline Sample & Torque Difference $\left(\mathbf{T}_{\mathbf{0}}-\mathbf{T}_{\mathbf{f}}\right) \mathbf{( N \cdot \mathbf { c m } )}$ \\
\hline F1 & 9.43 \\
F2 & 39.14 \\
F3 & 29.00 \\
\hline F4 & 41.29 \\
F5 & 41.86 \\
F6 & 39.00 \\
\hline F7 & 33.00 \\
F8 & 34.14 \\
F9 & 36.00 \\
\hline F10 & 26.86 \\
F11 & 20.00 \\
F12 & 25.14 \\
\hline F13 & 28.00 \\
F14 & 30.57 \\
\hline
\end{tabular}

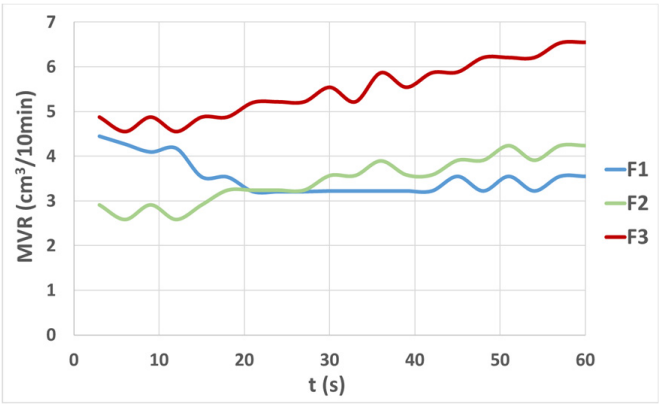

(a)

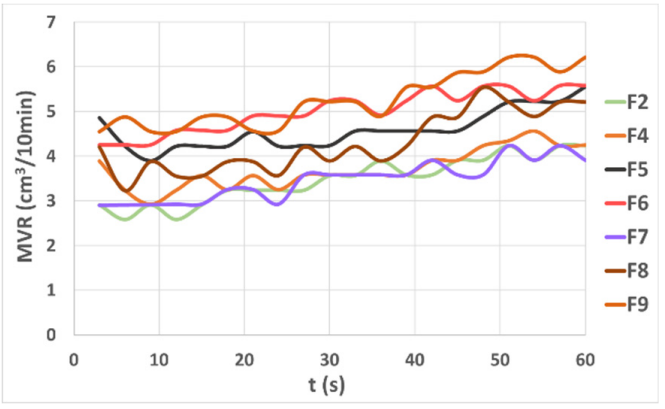

(b)

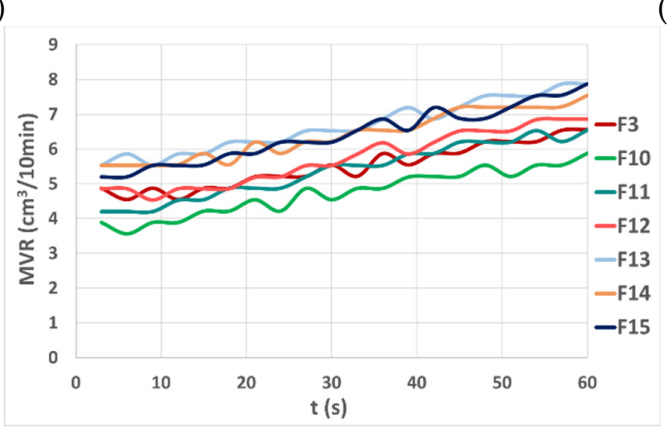

(c)

Figure 3. MVR values of: (a) pure matrix (F1) and untreated HSP (F2, F3); (b) pure H0210 (F2) and with different concentration of ESO+MA (F4, F5, F6) and ESO/SA (F7, F8, F9); (c) pure HM200 (F2) and with different concentration of ESO+MA (F10, F11, F12) and ESO/SA (F13, F14, F15).

\subsection{Thermal Characterization}

The evaluation of the thermal properties of the final composites was performed on all the prepared samples to investigate the effect of HSP and the ESO/DCA systems on the 
main thermal transition and the crystallinity of PLA. The obtained results were reported in Table 4.

Table 4. Identification of the main transition temperatures and crystallinity.

\begin{tabular}{|c|c|c|c|c|c|}
\hline Sample & PLA $_{\mathrm{g}}\left({ }^{\circ} \mathrm{C}\right)$ & $\operatorname{PBSA~T}_{\mathrm{m}}\left({ }^{\circ} \mathrm{C}\right)$ & PLA T $\mathrm{cc}\left({ }^{\circ} \mathrm{C}\right)$ & PLA $T_{m}\left({ }^{\circ} \mathrm{C}\right)$ & $X_{\text {C,PLA }}(\%)$ \\
\hline $\mathrm{F} 1$ & 57.64 & 82.62 & 117.83 & 150.01 & 4.2 \\
\hline $\mathrm{F} 2$ & 57.06 & 86.19 & 117.27 & 150.00 & 4.8 \\
\hline F3 & 55.68 & 85.86 & 114.22 & 149.15 & 4.3 \\
\hline $\mathrm{F} 4$ & 57.43 & 86.46 & 119.09 & 150.67 & 2.2 \\
\hline F5 & 56.97 & 85.99 & 117.21 & 149.83 & 3.1 \\
\hline F6 & 56.62 & 86.26 & 117.29 & 149.99 & 4.6 \\
\hline F7 & 57.62 & 86.26 & 118.47 & 150.43 & 4.4 \\
\hline F8 & 57.32 & 86.77 & 118.24 & 150.74 & 3.6 \\
\hline F9 & 56.48 & 86.24 & 117.14 & 149.89 & 7.3 \\
\hline F10 & 56.67 & 86.31 & 113.40 & 149.50 & 6.3 \\
\hline F11 & 55.61 & 86.11 & 111.45 & 148.66 & 6.5 \\
\hline F12 & 55.62 & 86.05 & 112.37 & 148.76 & 6.7 \\
\hline F13 & 56.10 & 85.80 & 112.89 & 148.90 & 6.4 \\
\hline F14 & 55.50 & 85.91 & 112.83 & 148.97 & 5.4 \\
\hline F15 & 55.71 & 85.78 & 111.87 & 148.45 & 7.2 \\
\hline
\end{tabular}

A general assessment of the effect of biocomposite production on the main thermal transition revealed a main effect of the $\mathrm{T}_{\mathrm{cc}}$ and crystallinity of PLA rather than the other temperatures. Small differences can be noticed in the $T_{g}$ of PLA where the biocomposites with the HM200 showed a shift to lower values. The melting temperature of PBSA was increased by $3-4{ }^{\circ} \mathrm{C}$ with the addition of the HSP while the PLA melting temperature remained almost unchanged. Instead, the crystallinity of PLA was not influenced by the addition of HSP as by the ESO/DCA system. In fact, the addition of both ESO/DCA systems in the composites with $\mathrm{H} 0210$ induced a reduction of crystallinity, while in the case of HM200 the final crystallinity resulted higher. It can be hypothesized that a concurrent mechanism between the formation of a crosslinked network, that interfered with the ordering of chains, and the effect of the filler as a nucleating agent, where in the $\mathrm{H} 0210$ the first mechanism and in HM200 the second prevailed (because of the higher surface area).

\subsection{Mechanical Characterization}

Tensile test results, reported in Table 5, obtained for materials after reactive extrusion showed the effect of the systems ESO/DCA on the compatibilization of HSP and the final properties of biocomposites.

Table 5. Mechanical properties for PLA-based blends.

\begin{tabular}{ccccc}
\hline Sample & $\left.\boldsymbol{\sigma}_{\mathbf{y}} \mathbf{( M P a}\right)$ & $\boldsymbol{\varepsilon}_{\mathbf{y}} \mathbf{( \% )}$ & $\boldsymbol{\sigma}_{\mathbf{b}} \mathbf{( M P a )}$ & $\boldsymbol{\varepsilon}_{\mathbf{b}}(\mathbf{\%})$ \\
\hline F1 & $28.8 \pm 0.7$ & $4.5 \pm 0.4$ & $25.2 \pm 1.3$ & $170.1 \pm 56.4$ \\
F2 & $29.8 \pm 2.6$ & $3.7 \pm 0.6$ & $25.4 \pm 4.6$ & $7.2 \pm 1.9$ \\
F3 & $23.8 \pm 0.5$ & $5.0 \pm 0.4$ & $19.7 \pm 0.7$ & $22.6 \pm 6.4$ \\
\hline F4 & $30.7 \pm 1.9$ & $3.9 \pm 0.5$ & $28.2 \pm 2.3$ & $7.0 \pm 3.5$ \\
F5 & $27.4 \pm 7.8$ & $3.8 \pm 0.4$ & $27.3 \pm 1$ & $7.0 \pm 1.8$ \\
F6 & $29.6 \pm 1.5$ & $4.0 \pm 0.5$ & $26.7 \pm 2$ & $9.3 \pm 4.8$ \\
\hline F7 & $30.0 \pm 1.9$ & $3.8 \pm 0.3$ & $25.3 \pm 7.5$ & $6.2 \pm 1.2$ \\
F8 & $28.0 \pm 1.8$ & $3.7 \pm 0.4$ & $25.6 \pm 1.3$ & $6.0 \pm 1.5$ \\
F9 & $27.6 \pm 1.9$ & $3.7 \pm 0.3$ & $24.2 \pm 1.8$ & $6.9 \pm 1.6$ \\
\hline F10 & $23.2 \pm 0.9$ & $4.5 \pm 0.3$ & $18.5 \pm 0.7$ & $21.2 \pm 6.9$ \\
F11 & $23.0 \pm 0.7$ & $4.2 \pm 0.2$ & $18.3 \pm 0.9$ & $23.4 \pm 6.5$ \\
F12 & $21.8 \pm 0.5$ & $4.2 \pm 0.6$ & $17.1 \pm 0.6$ & $29.5 \pm 5.5$ \\
\hline F13 & $22.8 \pm 0.6$ & $4.4 \pm 0.3$ & $18.2 \pm 0.7$ & $22.9 \pm 7.3$ \\
F14 & $22.4 \pm 0.6$ & $4.3 \pm 0.3$ & $17.5 \pm 0.8$ & $21.5 \pm 7.4$ \\
\hline F15 & $21.7 \pm 1.1$ & $4.0 \pm 0.5$ & $28.6 \pm 10.5$ \\
\hline
\end{tabular}


Elongation at break of PLA/PBSA blend underwent an important reduction after the mixing with HSP, changing from a very ductile material towards a much more fragile one, as deductible comparing the results of F2 and F3 with F1. This is a well-known behavior of biocomposites caused by the presence of the filler that reduces the bearing section and acts as a stress concentrator. The reduced dimension of the finer particles results then in a higher elongation at break and at yield in respect to the coarser ones. Regarding both the yield stress and stress at break, the pure matrix and the composites with the coarser HSP showed similar values while the HM200 had lower values. The addition of ESO/DCA showed a similar trend in all the samples with a decrement at higher concentration of additive, in agreement with the effect of a plasticizer in a polymer matrix. The effect of $\mathrm{SA} / \mathrm{ESO}$ and MA/ESO was very similar but it is possible to identify slightly higher stress values using the MA/ESO systems.

\subsection{Reactivity Study}

The reaction between ESO/DCA and the HM200 particles was investigated by infrared spectroscopy to verify its effectiveness. In Figure 4, a scheme of the supposed reaction that may occur in the melt in the interfacial region between filler and matrix between HSP, ESO, DCA, and PLA (representing biopolyesters in the composite) was reported.

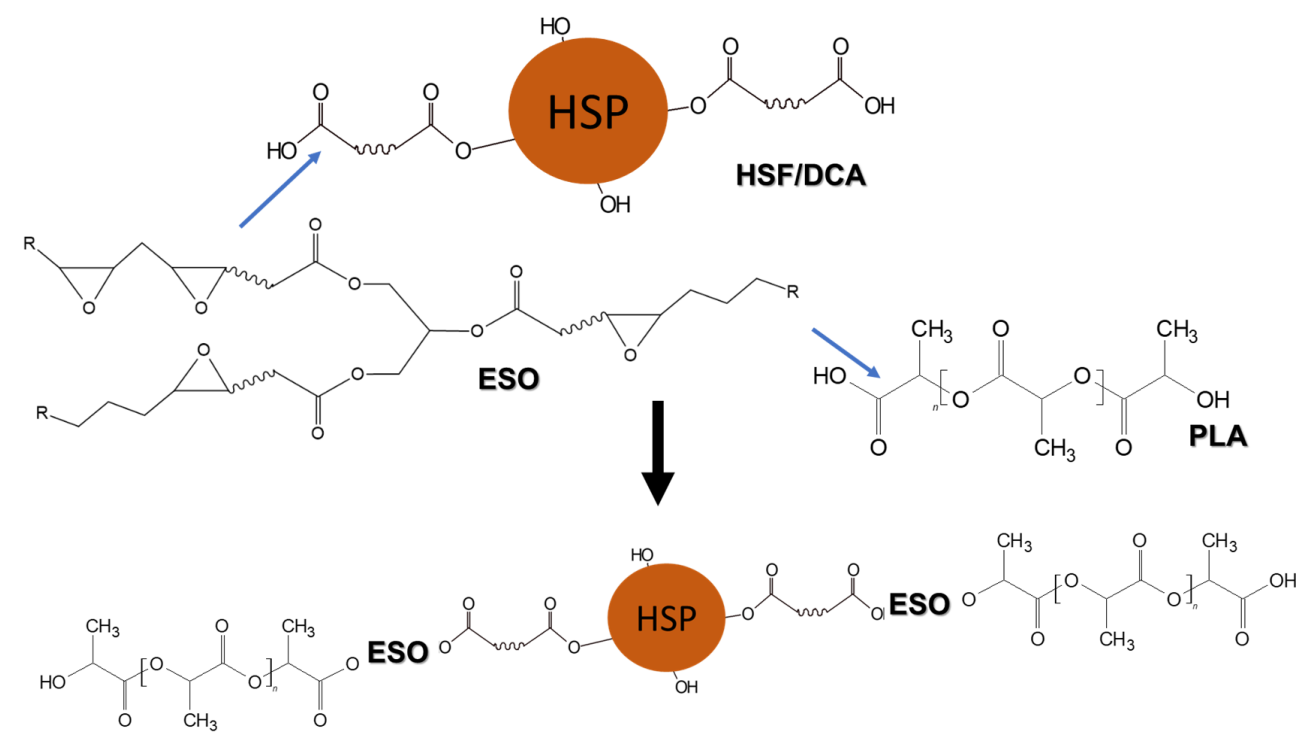

Figure 4. Scheme of the reaction occurring between HSP, ESO/DCA, and biopolyester matrix.

According to this scheme, a stable bond between HSP and biopolyesters was formed after the reaction. For this reason, the investigation of composite with infrared spectroscopy after dissolution in chloroform of the matrix can give information about this reaction. In fact, the presence of bonded PLA (or PBSA) resulted in additional signals in the spectrum of F12 and F15 samples.

In Figure 5, the comparison between the pure matrix and the pure HSP and their resulting composite (F3) after dissolution and filtering in chloroform was reported. It was possible to notice the absence of F1 signals in F3 spectrum that resembled HM200 except for the $\mathrm{C}-\mathrm{H}$ stretching signals at $2920 \mathrm{~cm}^{-1}$ and $2860 \mathrm{~cm}^{-1}$ that were clearly visible in the HM200 spectrum while in F3 they change in a wide broad band.

The investigation of ESO/DCA effect on HSP was reported in Figure 6 where it was possible to notice some differences in the spectra especially in the fingerprint region. In particular it was possible to observe an increment in the $1730 \mathrm{~cm}^{-1}$ band intensity that could be attributed to $\mathrm{C}=\mathrm{O}$ stretching in the $\mathrm{F} 12$ and $\mathrm{F} 15$ samples corresponding to the composites with MA/ESO and SA/ESO. This increment in the band could be attributed to the ester $\mathrm{C}=\mathrm{O}$ of the PLA (or PBSA) that remains bonded to HSP. 


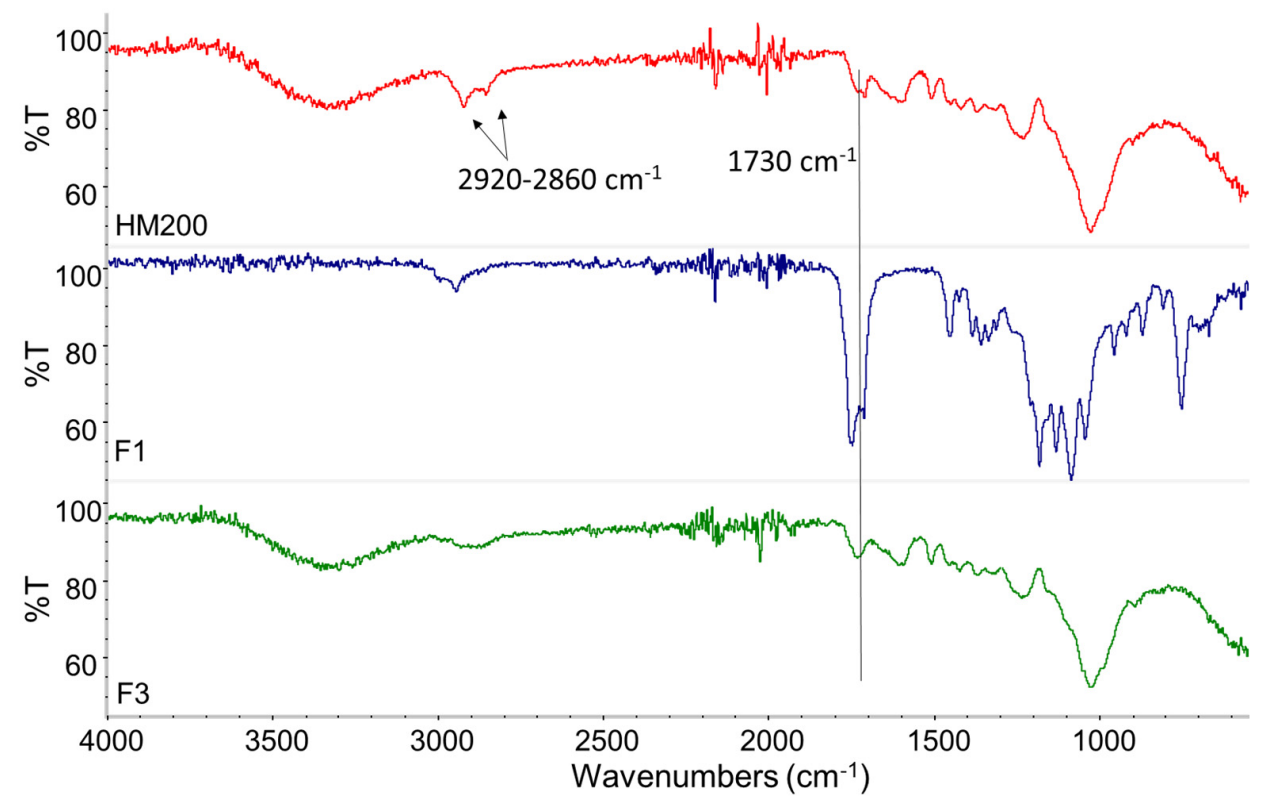

Figure 5. Comparison of the FTIR spectra of HM200 composite and the pure matrix and HSP.

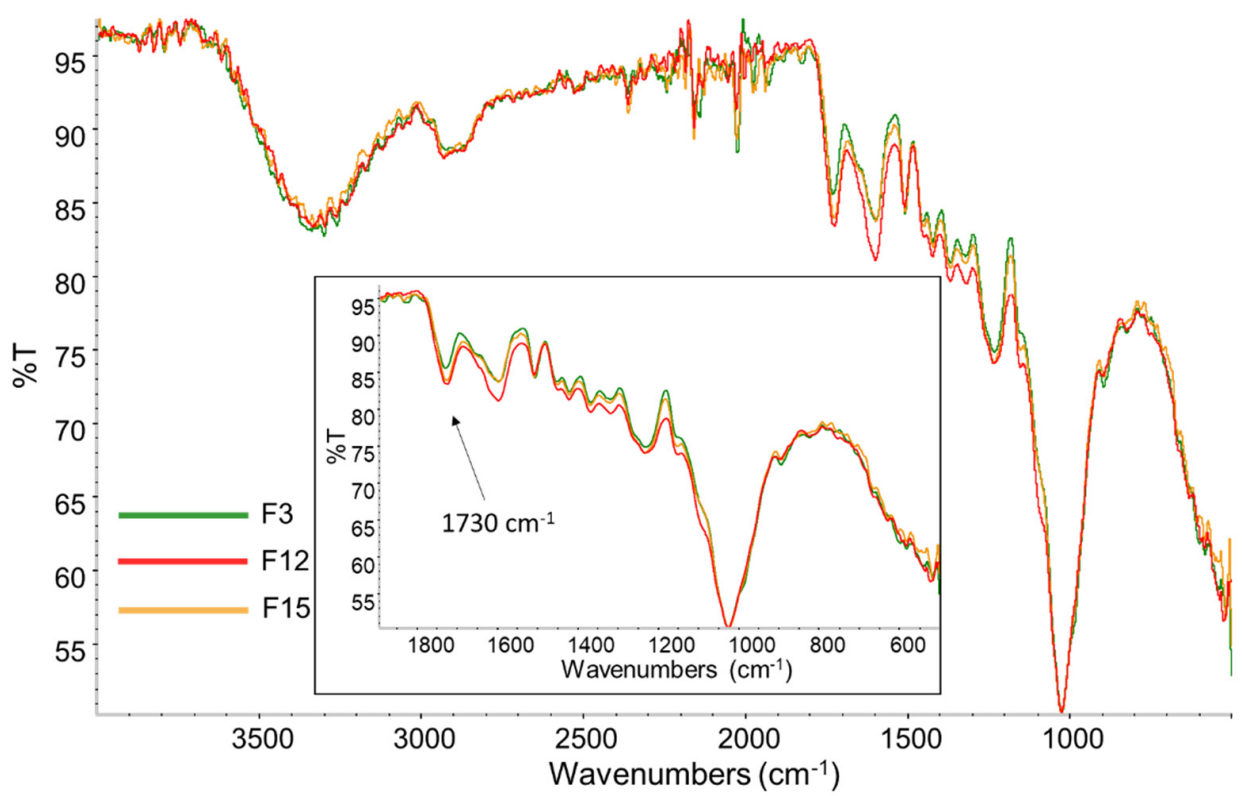

Figure 6. Comparison of the FTIR spectra of composites produced with unmodified HSP (F3) and HSP modified with MA/ESO (F12) and SA/ESO (F15).

\section{Discussion}

Despite the occurrence of some grafting onto the HSP surface, demonstrated by IR analysis, the impact onto melt fluidity and properties of ESO/DCA biobased chain extender was modest. Hence, the adopted characterization methodologies evidenced mainly slight chain scission effects in the explored ESO/DCA content range.

The trend of MVR as a function of ESO/DCA content in biocomposites, reported in Figures 7 and 8, confirmed the predominance of chain scission in respect to the chain extension, except for the sample based on HM200 (lower dimension) with ESO/MA, where a minimum in MVR can be identified at concentration of about $0.5 \mathrm{wt} . \%$. This behavior, already observed in similar biocomposites based on bran [47], evidenced a limit in concentration for these systems. Moreover, biocomposites with bran were more degraded from MA while in the systems containing HSP the best results were reached with this type 
of dicarboxylic acid. These results can be explained assuming a significant reactivity of ESO/MA that mainly caused chain scission in bran biocomposites. The differences observed for bran and HSP biocomposites can be ascribed to the different compositions of the two fillers. In fact, bran contains starch that is not present in HSP. Starch was found responsible of strong molecular weight reduction in PLA/PBSA blends [75]. Moreover, bran and HSP have different contents of lignin ( $6 \mathrm{wt} . \%$ and $39 \mathrm{wt} . \%$, respectively), a macromolecular material that can form complexes with ESO [76] but that can be considered less reactive than polysaccharides (like cellulose and starch) because of its highly cross-linked mainly aromatic rigid structure.

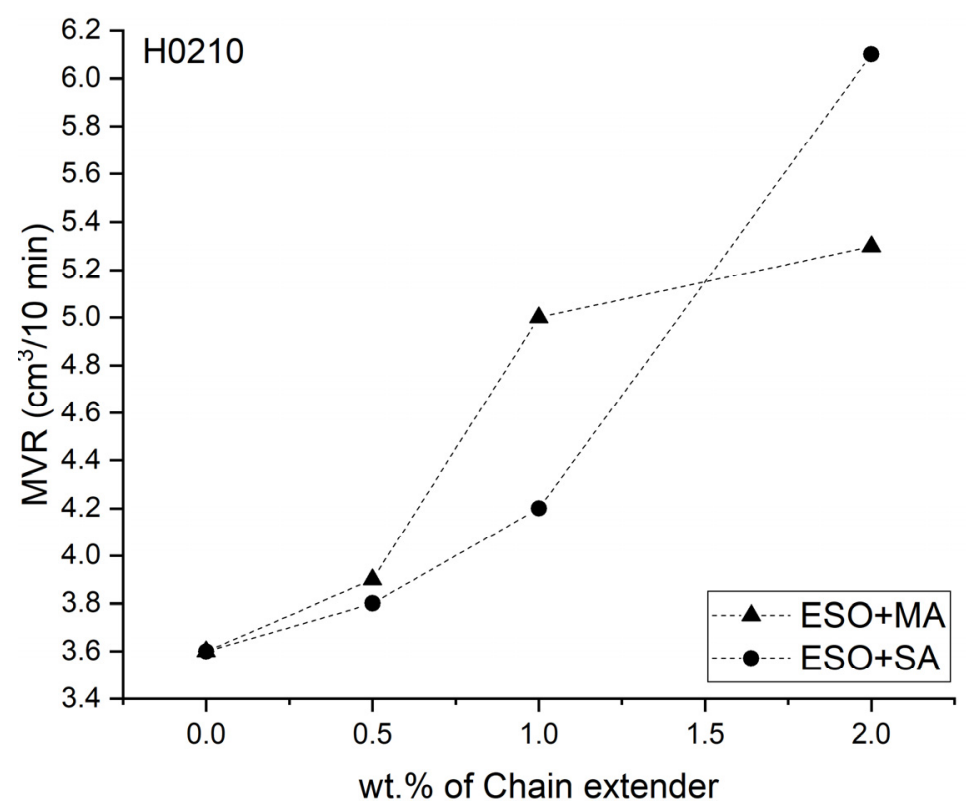

Figure 7. MVR trend for biocomposites based on H0210 HSP.

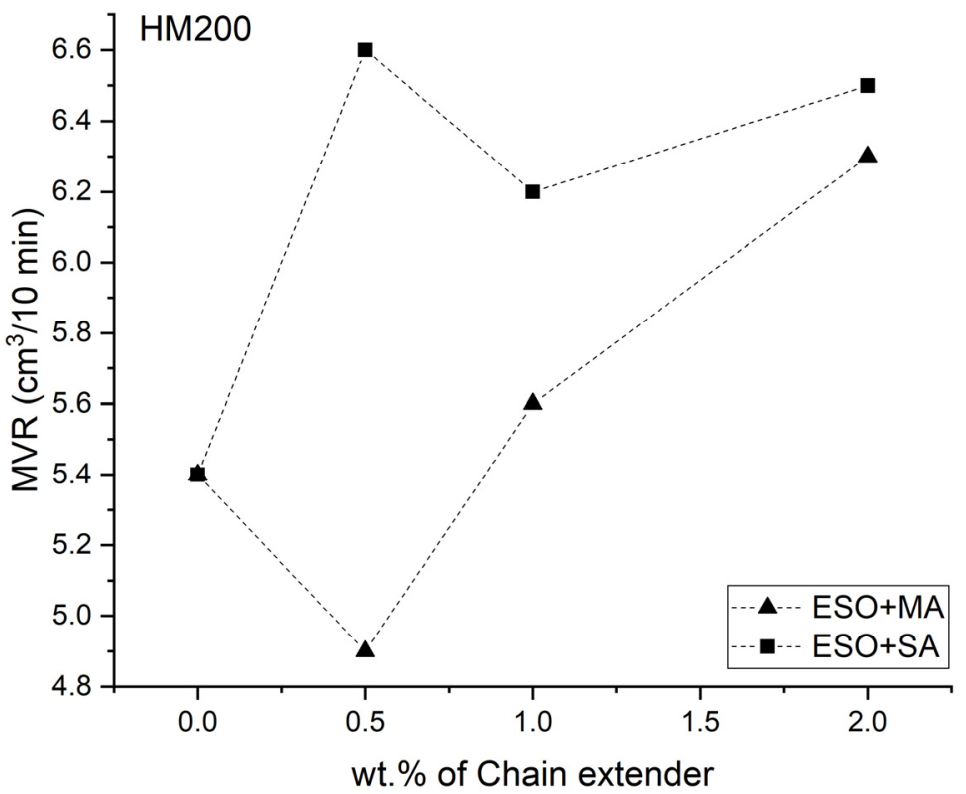

Figure 8. MVR trend for biocomposites based on HM200 HSP.

\section{Conclusions}

Innovative biobased chain extenders obtained with the use of epoxidized soybean oil (ESO) and malic acid (MA) or succinic acid (SA) were added in biocomposites composed 
by a PLA/PBSA blend matrix reinforced with hazelnut shell powders (HSPs) having two different dimensions.

Integrating the data of torque recorded during extrusion and melt volume rate measured on the prepared biocomposites, it was possible to investigate the system as a function of the adopted dicarboxylic acid (DCA), the ESO/DCA content, and the dimension of HSP reinforcement.

Melt viscosity studies showed that the ESO/DCA had a modest effect as a chain extender in these biocomposites. The best result was obtained by using ESO/SA, but only with the finest HSP dimension and at a low concentration of ESO/SA. This suggested that HSP was involved in the chain extension mechanism through the functional groups present on its surface. The occurrence of reactions involving HSP was evidenced by band intensity changes in IR spectra before and after the crosslinking reaction.

Thermal analysis revealed a significant effect of ESO/DCA systems on the crystallinity. In particular, the H0210 systems modified with both ESO/DCA showed a reduction of crystallinity in all its composites while the HM200 showed the opposite trend. The mechanism could be attributed to the crosslinking limiting the crystallization in the case of H0210 and a high effect of the HM200 as a nucleating agent. Tensile tests were not significantly influenced by the ESO/DCA systems that mainly depend on the dimension of HSPs used.

The present work can be compared with a previous work related to biocomposites incorporating bran. HSP biocomposites were less affected by chain scission than bran-based ones, but in bran-based biocomposites the ESO/SA system resulted in a wider concentration range more effective than in HSP composites. Moreover, in HSP biocomposites malic acid was more effective than succinic acid. The differences can be tentatively ascribed to the different compositions of the two fillers; despite this, this highly complex topic would require more research activity in the future.

In general, this work promoted the understanding of processes occurring in melt polymers incorporating a significant agro-food waste, allowing their potentialities to be better explored.

Author Contributions: Conceptualization, M.-B.C.; Methodology, L.P. and A.V.; Investigation, L.P. and A.V.; Resources, M.-B.C., D.B.; Data curation, M.-B.C., L.P., A.V. and L.A.; Writing-original draft preparation, L.P., and M.-B.C.; Writing-review and editing, L.P., M.-B.C., L.A., D.B. and A.L.; Visualization, L.P. and M.-B.C.; Supervision, A.L.; Project administration, M.-B.C. All authors have read and agreed to the published version of the manuscript.

Funding: This research received no external funding.

Institutional Review Board Statement: Not applicable.

Informed Consent Statement: Not applicable.

Data Availability Statement: The data presented in this study are available on request from the corresponding author.

Acknowledgments: OENO s.r.l. is thanked for providing L-malic acid from renewable sources. Total Corbion is thanked for providing PLA.

Conflicts of Interest: The authors declare no conflict of interest.

\section{References}

1. Muhammad Shamsuddin, I. Bioplastics as Better Alternative to Petroplastics and Their Role in National Sustainability: A Review. Adv. Biosci. Bioeng. 2017, 5, 63. [CrossRef]

2. Hottle, T.A.; Bilec, M.M.; Landis, A.E. Biopolymer production and end of life comparisons using life cycle assessment. Resour. Conserv. Recycl. 2017, 122, 295-306. [CrossRef]

3. Okamoto, M.; John, B. Synthetic biopolymer nanocomposites for tissue engineering scaffolds. Prog. Polym. Sci. 2013, 38, 1487-1503. [CrossRef]

4. Azimi, B.; Maleki, H.; Zavagna, L.; la Ossa, J.G.; Linari, S.; Lazzeri, A.; Danti, S. Bio-Based Electrospun Fibers for Wound Healing. J. Funct. Biomater. 2020, 11, 67. [CrossRef] [PubMed] 
5. Coltelli, M.-B.; Danti, S.; De Clerck, K.; Lazzeri, A.; Morganti, P. Pullulan for Advanced Sustainable Body- and Skin-Contact Applications. J. Funct. Biomater. 2020, 11, 20. [CrossRef] [PubMed]

6. Cristallini, C.; Danti, S.; Azimi, B.; Tempesti, V.; Ricci, C.; Ventrelli, L.; Cinelli, P.; Barbani, N.; Lazzeri, A. Multifunctional Coatings for Robotic Implanted Device. Int. J. Mol. Sci. 2019, 20, 5126. [CrossRef] [PubMed]

7. Song, J.; Winkeljann, B.; Lieleg, O. Biopolymer-Based Coatings: Promising Strategies to Improve the Biocompatibility and Functionality of Materials Used in Biomedical Engineering. Adv. Mater. Interfaces 2020, 7, 2000850. [CrossRef]

8. Rusa, C.C.; Shuai, X.; Shin, I.D.; Bullions, T.A.; Wei, M.; Porbeni, F.E.; Lu, J.; Huang, L.; Fox, J.; Tonelli, A.E. Controlling the Behaviors of Biodegradable/Bioabsorbable Polymers with Cyclodextrins. J. Polym. Environ. 2004, 12, 157-163. [CrossRef]

9. Kaplan, D.L. Introduction to Biopolymers from Renewable Resources. In Biopolymers from Renewable Resources; Kaplan, D.L., Ed.; Springer: Berlin/Heidelberg, Germany, 1998; pp. 1-29, ISBN 978-3-662-03680-8.

10. Lezak, E.; Kulinski, Z.; Masirek, R.; Piorkowska, E.; Pracella, M.; Gadzinowska, K. Mechanical and Thermal Properties of Green Polylactide Composites with Natural Fillers. Macromol. Biosci. 2008, 8, 1190-1200. [CrossRef]

11. Jappes, J.T.W.; Senthil Muthu Kumar, T.; Rajini, N.; Muthulaksmi, L.; Jawaid, M.; Varadharajulu, A. Preparation and Properties of Cellulose/Tamarind Nut Powder Green Composites. J. Nat. Fibers 2018, 15, 11-20. [CrossRef]

12. Badia, J.D.; Strömberg, E.; Kittikorn, T.; Ek, M.; Karlsson, S.; Ribes-Greus, A. Relevant factors for the eco-design of polylactide/sisal biocomposites to control biodegradation in soil in an end-of-life scenario. Polym. Degrad. Stab. 2017, 143, 9-19. [CrossRef]

13. Brebu, M. Environmental Degradation of Plastic Composites with Natural Fillers-A Review. Polymers 2020, 12, 166. [CrossRef]

14. Shah, A.A.; Hasan, F.; Hameed, A.; Ahmed, S. Biological degradation of plastics: A comprehensive review. Biotechnol. Adv. 2008, 26, 246-265. [CrossRef]

15. Ledbetter, C.A. Shell cracking strength in almond (Prunus dulcis [Mill.] D.A. Webb.) and its implication in uses as a value-added product. Bioresour. Technol. 2008, 99, 5567-5573. [CrossRef]

16. Lin, C.S.K.; Pfaltzgraff, L.A.; Herrero-Davila, L.; Mubofu, E.B.; Abderrahim, S.; Clark, J.H.; Koutinas, A.A.; Kopsahelis, N.; Stamatelatou, K.; Dickson, F.; et al. Food waste as a valuable resource for the production of chemicals, materials and fuels. Current situation and global perspective. Energy Environ. Sci. 2013, 6, 426-464. [CrossRef]

17. Essabir, H.; Achaby, M.E.I.; Hilali, E.I.M.; Bouhfid, R.; Qaiss, A. Morphological, Structural, Thermal and Tensile Properties of High Density Polyethylene Composites Reinforced with Treated Argan Nut Shell Particles. J. Bionic Eng. 2015, 12, 129-141. [CrossRef]

18. Jannat, N.; Latif Al-Mufti, R.; Hussien, A.; Abdullah, B.; Cotgrave, A. Utilisation of nut shell wastes in brick, mortar and concrete: A review. Constr. Build. Mater. 2021, 293, 123546. [CrossRef]

19. Ebikade, E.O.; Sadula, S.; Gupta, Y.; Vlachos, D.G. A review of thermal and thermocatalytic valorization of food waste. Green Chem. 2021, 23, 2806-2833. [CrossRef]

20. Rahib, Y.; Elorf, A.; Sarh, B.; Ezahri, M.; Rahib, Y.; Bonnamy, S. Experimental Analysis on Thermal Characteristics of Argan Nut Shell (ANS) Biomass as a Green Energy Resource. Int. J. Renew. Energy Res. 2019, 9, 1606-1615.

21. Rahib, Y.; Boushaki, T.; Sarh, B.; Chaoufi, J. Combustion and pollutant emission characteristics of argan nut shell (ANS) biomass. Fuel Process. Technol. 2021, 213, 106665. [CrossRef]

22. Rawlins, C.H.; Sadeghi, F. Experimental Study on Oil Removal in Nutshell Filters for Produced-Water Treatment. SPE Prod. Oper. 2017, 33, 145-153. [CrossRef]

23. Moccia, F.; Agustin-Salazar, S.; Berg, A.-L.; Setaro, B.; Micillo, R.; Pizzo, E.; Weber, F.; Gamez-Meza, N.; Schieber, A.; Cerruti, P.; et al. Pecan (Carya illinoinensis (Wagenh.) K. Koch) Nut Shell as an Accessible Polyphenol Source for Active Packaging and Food Colorant Stabilization. ACS Sustain. Chem. Eng. 2020, 8, 6700-6712. [CrossRef]

24. Haykiri-Acma, H.; Yaman, S.; Kucukbayrak, S. Comparison of the thermal reactivities of isolated lignin and holocellulose during pyrolysis. Fuel Process. Technol. 2010, 91, 759-764. [CrossRef]

25. Esposito, T.; Sansone, F.; Franceschelli, S.; Del Gaudio, P.; Picerno, P.; Aquino, R.P.; Mencherini, T. Hazelnut (Corylus avellana L.) Shells Extract: Phenolic Composition, Antioxidant Effect and Cytotoxic Activity on Human Cancer Cell Lines. Int. J. Mol. Sci. 2017, 18, 392. [CrossRef] [PubMed]

26. Xu, Y.; Sismour, E.N.; Parry, J.; Hanna, M.A.; Li, H. Nutritional composition and antioxidant activity in hazelnut shells from US-grown cultivars. Int. J. Food Sci. Technol. 2012, 47, 940-946. [CrossRef]

27. Balart, J.F.; García-Sanoguera, D.; Balart, R.; Boronat, T.; Sánchez-Nacher, L. Manufacturing and properties of biobased thermoplastic composites from poly(lactid acid) and hazelnut shell wastes. Polym. Compos. 2018, 39, 848-857. [CrossRef]

28. Teuber, L.; Osburg, V.-S.; Toporowski, W.; Militz, H.; Krause, A. Wood polymer composites and their contribution to cascading utilisation. J. Clean. Prod. 2016, 110, 9-15. [CrossRef]

29. Keener, T.J.; Stuart, R.K.; Brown, T.K. Maleated coupling agents for natural fibre composites. Compos. Part A Appl. Sci. Manuf. 2004, 35, 357-362. [CrossRef]

30. Maldas, D.; Kokta, B.V.; Daneault, C. Influence of coupling agents and treatments on the mechanical properties of cellulose fiber-polystyrene composites. J. Appl. Polym. Sci. 1989, 37, 751-775. [CrossRef]

31. Aliotta, L.; Lazzeri, A. A proposal to modify the Kelly-Tyson equation to calculate the interfacial shear strength (IFSS) of composites with low aspect ratio fibers. Compos. Sci. Technol. 2020, 186, 107920. [CrossRef]

32. Tillet, G.; Boutevin, B.; Ameduri, B. Chemical reactions of polymer crosslinking and post-crosslinking at room and medium temperature. Prog. Polym. Sci. 2011, 36, 191-217. [CrossRef] 
33. Lee, T.; Lee, C.; Cho, S.; Lee, D.; Yoon, K.-B. Enhancement of physical properties of thermoplastic polyether-ester elastomer by reactive extrusion with chain extender. Polym. Bull. 2011, 66, 979-990. [CrossRef]

34. Frenz, V.; Scherzer, D.; Villalobos, M.; Awojulu, A.; Edison, M.; Meer, R. Multifunctional Polymers as Chain Extenders and Compatibilizers for Polycondensates and Biopolymers. In Proceedings of the Technical Papers, Regional Technical ConferenceSociety of Plastics Engineers, Wyandotte, MI, USA, 4-8 May 2008; Volume 3.

35. Kahraman, Y.; Özdemir, B.; Kılıç, V.; Goksu, Y.A.; Nofar, M. Super toughened and highly ductile PLA/TPU blend systems by in situ reactive interfacial compatibilization using multifunctional epoxy-based chain extender. J. Appl. Polym. Sci. 2021, 138, 50457. [CrossRef]

36. de CD Nunes, E.; de Souza, A.G.; dos S Rosa, D. Use of a chain extender as a dispersing agent of the CaCO3 into PBAT matrix. J. Compos. Mater. 2020, 54, 1373-1382. [CrossRef]

37. Liu, C.; Jia, Y.; He, A. Preparation of Higher Molecular Weight Poly (L-lactic Acid) by Chain Extension. Int. J. Polym. Sci. 2013, 2013, 315917. [CrossRef]

38. Beltrán, F.R.; Infante, C.; de la Orden, M.U.; Martínez Urreaga, J. Mechanical recycling of poly(lactic acid): Evaluation of a chain extender and a peroxide as additives for upgrading the recycled plastic. J. Clean. Prod. 2019, 219, 46-56. [CrossRef]

39. Pilla, S.; Kramschuster, A.; Yang, L.; Lee, J.; Gong, S.; Turng, L.-S. Microcellular injection-molding of polylactide with chainextender. Mater. Sci. Eng. C 2009, 29, 1258-1265. [CrossRef]

40. Arruda, L.C.; Magaton, M.; Bretas, R.E.S.; Ueki, M.M. Influence of chain extender on mechanical, thermal and morphological properties of blown films of PLA/PBAT blends. Polym. Test. 2015, 43, 27-37. [CrossRef]

41. Najafi, N.; Heuzey, M.C.; Carreau, P.J. Polylactide (PLA)-clay nanocomposites prepared by melt compounding in the presence of a chain extender. Compos. Sci. Technol. 2012, 72, 608-615. [CrossRef]

42. Li, X.; Ai, X.; Pan, H.; Yang, J.; Gao, G.; Zhang, H.; Yang, H.; Dong, L. The morphological, mechanical, rheological, and thermal properties of PLA/PBAT blown films with chain extender. Polym. Adv. Technol. 2018, 29, 1706-1717. [CrossRef]

43. Anakabe, J.; Zaldua Huici, A.M.; Eceiza, A.; Arbelaiz, A. The effect of the addition of poly(styrene-co-glycidyl methacrylate) copolymer on the properties of polylactide/poly(methyl methacrylate) blend. J. Appl. Polym. Sci. 2016, 133. [CrossRef]

44. Chaiwutthinan, P.; Leejarkpai, T.; Kashima, D.P.; CHUAYJULJIT, S. Poly(Lactic Acid)/Poly(Butylene Succinate) Blends Filled with Epoxy Functionalised Polymeric Chain Extender. Adv. Mater. Res. 2013, 664, 644-648. [CrossRef]

45. Cao, Z.; Lu, Y.; Zhang, C.; Zhang, Q.; Zhou, A.; Hu, Y.; Wu, D.; Tao, G.; Gong, F.; Ma, W.; et al. Effects of the chain-extender content on the structure and performance of poly(lactic acid)-poly(butylene succinate)-microcrystalline cellulose composites. J. Appl. Polym. Sci. 2017, 134. [CrossRef]

46. Bobade, S.K.; Paluvai, N.R.; Mohanty, S.; Nayak, S.K. Bio-Based Thermosetting Resins for Future Generation: A Review. Polym. Plast. Technol. Eng. 2016, 55, 1863-1896. [CrossRef]

47. Coltelli, M.-B.; Bertolini, A.; Aliotta, L.; Gigante, V.; Vannozzi, A.; Lazzeri, A. Chain Extension of Poly(Lactic Acid) (PLA)-Based Blends and Composites Containing Bran with Biobased Compounds for Controlling Their Processability and Recyclability. Polymers 2021, 13, 3050. [CrossRef]

48. Sharma, B.K.; Adhvaryu, A.; Liu, Z.; Erhan, S.Z. Chemical modification of vegetable oils for lubricant applications. J. Am. Oil Chem. Soc. 2006, 83, 129-136. [CrossRef]

49. Sharmin, E.; Zafar, F.; Akram, D.; Alam, M.; Ahmad, S. Recent advances in vegetable oils based environment friendly coatings: A review. Ind. Crops Prod. 2015, 76, 215-229. [CrossRef]

50. Alam, M.; Akram, D.; Sharmin, E.; Zafar, F.; Ahmad, S. Vegetable oil based eco-friendly coating materials: A review article. Arab. J. Chem. 2014, 7, 469-479. [CrossRef]

51. No, S.-Y. Inedible vegetable oils and their derivatives for alternative diesel fuels in CI engines: A review. Renew. Sustain. Energy Rev. 2011, 15, 131-149. [CrossRef]

52. Chieng, B.W.; Ibrahim, N.A.; Then, Y.Y.; Loo, Y.Y. Epoxidized Vegetable Oils Plasticized Poly(lactic acid) Biocomposites: Mechanical, Thermal and Morphology Properties. Molecules 2014, 19, 16024-16038. [CrossRef] [PubMed]

53. Gamage, P.K.; O'Brien, M.; Karunanayake, L. Epoxidation of some vegetable oils and their hydrolysed products with peroxyformic acid-Optimised to industrial scale. J. Natl. Sci. Found. Sri Lanka 2009, 37, 229-240. [CrossRef]

54. Ferri, J.M.; Garcia-Garcia, D.; Montanes, N.; Fenollar, O.; Balart, R. The effect of maleinized linseed oil as biobased plasticizer in poly(lactic acid)-based formulations. Polym. Int. 2017, 66, 882-891. [CrossRef]

55. Garcia-Garcia, D.; Carbonell-Verdu, A.; Arrieta, M.P.; López-Martínez, J.; Samper, M.D. Improvement of PLA film ductility by plasticization with epoxidized karanja oil. Polym. Degrad. Stab. 2020, 179, 109259. [CrossRef]

56. Auvergne, R.; Caillol, S.; David, G.; Boutevin, B.; Pascault, J.-P. Biobased Thermosetting Epoxy: Present and Future. Chem. Rev. 2014, 114, 1082-1115. [CrossRef]

57. Xia, Y.; Quirino Rafael, L.; Larock, R.C. Biobased Thermosetting Polymers from Vegetable Oils. J. Renew. Mater. 2013, 1,3-27. [CrossRef]

58. Aliotta, L.; Gigante, V.; Coltelli, M.-B.; Lazzeri, A. Volume Change during Creep and Micromechanical Deformation Processes in PLA-PBSA Binary Blends. Polymers 2021, 13, 2379. [CrossRef]

59. Aliotta, L.; Vannozzi, A.; Bonacchi, D.; Coltelli, M.-B.; Lazzeri, A. Analysis, Development, and Scaling-Up of Poly(lactic acid) (PLA) Biocomposites with Hazelnuts Shell Powder (HSP). Polymers 2021, 13, 4080. [CrossRef] 
60. Aliotta, L.; Vannozzi, A.; Canesi, I.; Cinelli, P.; Coltelli, M.-B.; Lazzeri, A. Poly(lactic acid) (PLA)/Poly(butylene succinate-coadipate) (PBSA) Compatibilized Binary Biobased Blends: Melt Fluidity, Morphological, Thermo-Mechanical and Micromechanical Analysis. Polymers 2021, 13, 218. [CrossRef] [PubMed]

61. Zeng, R.-T.; Wu, Y.; Li, Y.-D.; Wang, M.; Zeng, J.-B. Curing behavior of epoxidized soybean oil with biobased dicarboxylic acids. Polym. Test. 2017, 57, 281-287. [CrossRef]

62. Li, A.; Li, K. Pressure-Sensitive Adhesives Based on Epoxidized Soybean Oil and Dicarboxylic Acids. ACS Sustain. Chem. Eng. 2014, 2, 2090-2096. [CrossRef]

63. Zhao, T.-H.; Wu, Y.; Li, Y.-D.; Wang, M.; Zeng, J.-B. High Performance and Thermal Processable Dicarboxylic Acid Cured Epoxidized Plant Oil Resins through Dynamic Vulcanization with Poly(lactic acid). ACS Sustain. Chem. Eng. 2017, 5, 1938-1947. [CrossRef]

64. Garea, S.-A.; Corbu, A.-C.; Deleanu, C.; Iovu, H. Determination of the epoxide equivalent weight (EEW) of epoxy resins with different chemical structure and functionality using GPC and 1H-NMR. Polym. Test. 2006, 25, 107-113. [CrossRef]

65. Yussuf, A.A.; Massoumi, I.; Hassan, A. Comparison of Polylactic Acid/Kenaf and Polylactic Acid/Rise Husk Composites: The Influence of the Natural Fibers on the Mechanical, Thermal and Biodegradability Properties. J. Polym. Environ. 2010, 18, 422-429. [CrossRef]

66. Sanivada, U.K.; Mármol, G.; Brito, F.P.; Fangueiro, R. PLA Composites Reinforced with Flax and Jute Fibers-A Review of Recent Trends, Processing Parameters and Mechanical Properties. Polymers 2020, 12, 2373. [CrossRef] [PubMed]

67. Sykacek, E.; Schlager, W.; Mundigler, N. Compatibility of softwood flour and commercial biopolymers in injection molding. Polym. Compos. 2010, 31, 443-451. [CrossRef]

68. Aliotta, L.; Gigante, V.; Coltelli, M.-B.; Cinelli, P.; Lazzeri, A.; Seggiani, M. Thermo-Mechanical Properties of PLA/Short Flax Fiber Biocomposites. Appl. Sci. 2019, 9, 3797. [CrossRef]

69. Yang, X.; Xu, H.; Odelius, K.; Hakkarainen, M. Poly(lactide)-g-poly(butylene succinate-co-adipate) with High Crystallization Capacity and Migration Resistance. Materials 2016, 9, 313. [CrossRef] [PubMed]

70. Patrício, T.; Bártolo, P. Thermal Stability of PCL/PLA Blends Produced by Physical Blending Process. Procedia Eng. 2013, 59, 292-297. [CrossRef]

71. Li, M.-X.; Kim, S.-H.; Choi, S.-W.; Goda, K.; Lee, W.-I. Effect of reinforcing particles on hydrolytic degradation behavior of poly (lactic acid) composites. Compos. Part B Eng. 2016, 96, 248-254. [CrossRef]

72. Elsawy, M.A.; Kim, K.-H.; Park, J.-W.; Deep, A. Hydrolytic degradation of polylactic acid (PLA) and its composites. Renew. Sustain. Energy Rev. 2017, 79, 1346-1352. [CrossRef]

73. Agustin-Salazar, S.; Cerruti, P.; Medina-Juárez, L.Á.; Scarinzi, G.; Malinconico, M.; Soto-Valdez, H.; Gamez-Meza, N. Lignin and holocellulose from pecan nutshell as reinforcing fillers in poly (lactic acid) biocomposites. Int. J. Biol. Macromol. 2018, 115, 727-736. [CrossRef] [PubMed]

74. Al-Mulla, E.A.J.; Yunus, W.M.Z.W.; Ibrahim, N.A.B.; Rahman, M.Z.A. Properties of epoxidized palm oil plasticized polytlactic acid. J. Mater. Sci. 2010, 45, 1942-1946. [CrossRef]

75. Coltelli, M.-B.; Aliotta, L.; Vannozzi, A.; Morganti, P.; Panariello, L.; Danti, S.; Neri, S.; Fernandez-Avila, C.; Fusco, A.; Donnarumma, G.; et al. Properties and Skin Compatibility of Films Based on Poly(Lactic Acid) (PLA) Bionanocomposites Incorporating Chitin Nanofibrils (CN). J. Funct. Biomater. 2020, 11, 21. [CrossRef] [PubMed]

76. Thielemans, W.; Can, E.; Morye, S.S.; Wool, R.P. Novel applications of lignin in composite materials. J. Appl. Polym. Sci. 2002, 83, 323-331. [CrossRef] 